\title{
The Tumor Suppressor p53 Transcriptionally Regulates cGKI Expression during Neuronal Maturation and Is Required for cGMP-Dependent Growth Cone Collapse
}

\author{
Andrea Tedeschi, ${ }^{1,4}$ Tuan Nguyen, ${ }^{1}$ Sonya Ulrike Steele, ${ }^{1}$ Susanne Feil, ${ }^{3}$ Ulrike Naumann, ${ }^{2}$ Robert Feil, ${ }^{3}$ \\ and Simone Di Giovanni ${ }^{1}$ \\ ${ }^{1}$ Center for Neurology, Laboratory for NeuroRegeneration and Repair and 2Department of General Neurology, Laboratory for Molecular \\ Neuro-Oncology, Hertie Institute for Clinical Brain Research, ${ }^{3}$ Interfakultaeres Institut fuer Biochemie, and ${ }^{4}$ Graduate School of Cellular \& \\ Molecular Neuroscience, University of Tuebingen, D-72076 Tuebingen, Germany
}

The cGMP-dependent protein kinase type I (cGKI) has multiple functions including a role in axonal growth and pathfinding of sensory neurons, and counteracts Semaphorin $3 \mathrm{~A}$ (Sema3A)-induced growth cone collapse. Within the nervous system, however, the transcriptional regulation of cGKI is still obscure. Recently, the transcription factor and tumor suppressor p53 has been reported to promote neurite outgrowth by regulating the gene expression of factors that promote growth cone extension, but specific p53 targets genes that may counteract growth cone collapse have not been identified so far. Here, we show that p53 promotes cGKI expression in neuronal-like PC-12 cells and primary neurons by occupying specific regulatory elements in a chromatin environment during neuronal maturation. Importantly, we demonstrate that p53-dependent expression of cGKI is required for the ability of cGMP to counteract growth cone collapse. Growth cone retraction mediated by Sema3A is overcome by cGMP only in wild-type, but not in p53-null dorsal root ganglia. Reconstitution of 53 levels is sufficient to recover both cGKI expression and the ability of cGMP to counteract growth cone collapse, while cGKI overexpression rescues growth cone collapse in p53-null primary neurons.

In conclusion, this study identifies $\mathrm{p} 53$ as a transcription factor that regulates the expression of cGKI during neuronal maturation and cGMP-dependent inhibition of growth cone collapse.

\section{Introduction}

Neuronal maturation and outgrowth require a concerted sequence of molecular events that allow neurite extension, growth cone remodeling, and appropriate target innervation to occur.

We have recently demonstrated that the transcription factor and tumor suppressor p53 is required for neuronal maturation and peripheral nerve regeneration by driving the expression of pro-axonal outgrowth proteins expressed both in axons and at the growth cones (Di Giovanni et al., 2006; Tedeschi et al., 2009). However, appropriate neuronal maturation and successful regeneration require not only modulation of progrowth genes but also of factors that counteract growth cone collapse and repulsion. Therefore, we asked whether p53 is capable of regulating the transcription of such genes during neuronal maturation and neurite outgrowth. By performing an in silico analysis using a previ-

\footnotetext{
Received Sept. 8, 2009; revised Sept. 29, 2009; accepted 0ct. 10, 2009.

This work was supported by the Hertie Foundation, the International Foundation for Research in Paraplegia, National Institutes of Health Grant R21 NS052640, and Deutsche Forschungsgemeinschaft Grant DI 1497/1-1 (all granted to S.D.G.). We thank Dr. Bernd Knöll for providing the semaphorin $3 \mathrm{~A}$ expression plasmid. We are indebted to Dr. K. D. Bloch for providing the cGKI adenovirus.

Correspondence should be addressed to Dr. Simone Di Giovanni, Laboratory for NeuroRegeneration and Repair Hertie Institute for Clinical Brain Research, University of Tuebingen, Otfried-Mueller Strasse 27, D-72076 Tuebingen, Germany. E-mail: simone.digiovanni@medizin.uni-tuebingen.de.

D01:10.1523/JNEUROSCI.4416-09.2009

Copyright $\odot 2009$ Society for Neuroscience $\quad$ 0270-6474/09/2915155-06\$15.00/0
}

ously published algorithm (Hoh et al., 2002) we initially searched for p53 transcription factor binding sites (TFBS) on candidate genes involved in antagonizing growth cone collapse and repulsion signals. This analysis resulted in the identification of the cGMP-dependent protein kinase type I (cGKI) as a putative p53 target gene. In part by preventing growth cone collapse, a signaling pathway mediated via the second messenger cGMP and its effector kinase cGKI has been previously described to modulate the growth cone response to molecules influencing growth cone navigation such as Sema 3A during axonal guidance and projection of sensory neurons (Song et al., 1998; Schmidt et al., 2002, 2007). Importantly, cGKI is expressed at high levels in neurons undergoing development and it has been reported that cGKI-null mice have an impairment in cortical neurons dendritic arborization (Demyanenko et al., 2005), thus suggesting a role for cGKI during neuronal maturation.

Two cGKI isoforms, cGKIalpha and cGKIbeta, are known to be expressed from the cGKI gene (Butt et al., 1993). These isoforms differ only in the initial coding exon and have different expression patterns within the nervous system (Schmidt et al., 2002; Feil et al., 2005). While the up- and downstream components of the cGMP-cGKI pathway are being intensively explored (Schmidt et al., 2007; Zhao et al., 2009), the transcriptional regulation of cGKI in a neuronal chromatin environment has not been investigated yet. 
Here, we asked whether p53 is capable to regulate the gene expression of cGKI during neuronal maturation and whether this affects cGMP-dependent inhibition of growth cone collapse.

\section{Materials and Methods}

Cell culture: cell lines, primary cortical neurons, and dorsal root ganglion explants. Cells and tissues were obtained from wild-type (WT), p53-null (Di Giovanni et al., 2006), and cGKI-null (Wegener et al., 2002) mice. For further details, see supplemental information, available at www. jneurosci.org as supplemental material.

Real-time reverse transcriptase PCR analysis. cDNA $(1 \mu \mathrm{l})$ was used in a real-time reverse transcriptase (RT)-PCR using SYBR GreenER (Invitrogen). For further details, see supplemental information, available at www.jneurosci.org as supplemental material.

Clones and transfection experiments. pcDNA3 vector expressing dominant-negative forms of p53 were kindly provided by Dr. B. Vogelstein; the 553 mutant has a mutation at residue 175 (p53-R175H), and was V5-tagged in a CMV driven expression vector (Invitrogen) by us. See supplemental information, available at www.jneurosci.org as supplemental material, for details of the above experiments and of the luciferase assays.

RNA interference. Hairpin sequences were designed and synthesized (Invitrogen) with specific overhangs for cloning into the pENTR/U6 entry vector. See supplemental information, available at www.jneurosci. org as supplemental material, for details of the RNA interference as well as the viral construction, production, and infection.

Chromatin immunoprecipitation assays. Cultured cortical neurons were fixed in a $1 \%$ formaldehyde-PBS solution at $3 \mathrm{~d}$ in vitro (3 DIV). Following cell lysis ( $0.5 \%$ SDS, $100 \mathrm{~mm} \mathrm{NaCl}, 50 \mathrm{~mm}$ Tris HCl, ph 8.0, 5 mM EDTA), extracts were sonicated to shear DNA to lengths of 200-600 bp. See supplemental information, available at www.jneurosci.org as supplemental material, for details.

Antibodies. The following primary antibodies were used for immunoblotting (IB) and immunocytochemistry (ICC): rabbit anti-cGKI (DH) (Valtcheva et al., 2009) (1:5000 IB; 1:500 ICC); rabbit polyclonal anti-p53 (1:500 IB, Santa Cruz Biotechnology sc-6243); mouse monoclonal antip53 (1:1000 IB, Oncogene Ab1/Ab6); mouse monoclonal anti- $\beta$ III tubulin (1:1000 IB; 1:500 ICC, Promega); mouse monoclonal anti-V5 (1: 5000 IB, Invitrogen); anti-phalloidin Alexa Fluor 568 conjugated (1:50 ICC, Invitrogen); mouse monoclonal anti- $\beta$-actin (1:10,000 IB, Sigma). The generation of the polyclonal antiserum against cGKI that has been used in the present study has been described before (Valtcheva et al., 2009). This present antibody was prepared with the same procedure as a previous batch that had exquisite specificity for cGKI on murine brain sections (Feil et al., 2003, 2005; Paul et al., 2008). Indeed, in all our tests the present antibody behaved similarly to the old one. Importantly, it showed no signal on tissue sections (data not shown) or Western Blots of cGKI knock-out mice (Valtcheva et al., 2009).

Immunoblotting. For immunoblotting, proteins from cultured PC-12, primary E18 cortical neurons and dissected dorsal root ganglia (DRGs) were lysed, loaded on a gel and detected according to standard procedures. See supplemental information, available at www.jneurosci.org as supplemental material, for details.

Immunocytochemistry. Cells were grown on coverslips, and fixed with $4 \%$ paraformaldehyde $/ 4 \%$ sucrose and further fixation with $100 \%$ icecold methanol. Cells were blocked in $10 \%$ albumin and $0.2 \%$ Triton $\mathrm{X}-100$. Cells were incubated with the appropriate primary and secondary antibodies and signal was detected following standard procedures. See supplemental information, available at www.jneurosci.org as supplemental material, for details.

Time-lapse recording. Live imaging was performed in an inverted time lapse Zeiss microscope with a transmitted light detector. Images were taken at 20 min intervals. During recording, DRGs were maintained in a humidified atmosphere of $5 \% \mathrm{CO}_{2}$ in air at $37^{\circ} \mathrm{C}$.

Growth cone collapse assay. For the growth cone collapse assay, we followed the method reported by Schmidt et al. (2002). Briefly, postnatal day 7 (P7) DRG explants were grown on poly-D-lysine/laminin (Sigma) for $3 \mathrm{~d}$ in Dulbecco's modified medium supplemented with $10 \%$ fetal bovine serum (Invitrogen), $100 \mathrm{U} / \mathrm{ml}$ penicillin and $100 \mathrm{mg} / \mathrm{ml}$ streptomycin (Invitrogen) and NGF $(50 \mathrm{ng} / \mathrm{ml})$ in a humidified atmosphere of $5 \% \mathrm{CO}_{2}$ in air at $37^{\circ} \mathrm{C}$. Explants were pretreated with 8-Br-cGMP (100 $\mu \mathrm{M}$ ) for $30 \mathrm{~min}$ followed by incubation with supernatant from cultured COS7 cells that were transiently transfected with a Sema3A expression plasmid. COS7 supernatants were titrated to induce a collapse of $90-$ $100 \%$ of growth cones after $1 \mathrm{~h}$ at $37^{\circ} \mathrm{C}$. Collapse was defined and scored as a loss of lamellipodia and most filopodia (Luo et al., 1993).

In a set of experiments, p53-null DRGs were infected with GFP, p53 GFP and cGKI adenovirus after $24 \mathrm{~h}$ in culture and, before adding 8-BrcGMP, explants were treated with cGKI inhibitor (10 $\mu \mathrm{M}$ KT 5823, Biomol) for $30 \mathrm{~min}$. For each experimental condition, at least 200-300 growth cones were analyzed. To measure the area of the DRG explants, at least 100 explants were analyzed. Growth cones were viewed using a CCD camera and analyzed with the image analysis software AxioVision 3.1 (Zeiss). All experiments were performed in triplicate.

\section{Results}

\section{p53 is required for cGKI expression}

Initially, we used the pheochromocytoma PC-12 cell system to test the hypothesis that $\mathrm{p} 53$ would regulate the expression of cGKI, as both p53 and cGKI are expressed in this neuronal like cell line and promote NGF-dependent neurite outgrowth (Hughes et al., 2000; Yamazaki et al., 2004; Di Giovanni et al., 2006; Tedeschi et al., 2009).

We measured the mRNA levels of cGKI, including the two known isoforms cGKI $\alpha$ and $\beta$, in wild-type PC-12 cells and in cells stably transfected with a p53 dominant-negative construct (p53DN R175H). We also measured cGKI gene expression in PC-12 cells following p53 gene silencing by specific shRNA for p53. Both RT-PCR and quantitative RT-PCR revealed that cGKI expression was significantly reduced when p53 signaling was impaired (p53DN) (Fig. 1a,b) and when p53 expression was downregulated (p53 gene silencing) (Fig. 1c,d). As shown by immunoblotting, cGKI protein levels were also strongly reduced in PC-12 cells stably transfected with p53DN or after p53 gene silencing (Fig. 1e,f).

To investigate whether $\mathrm{p} 53$ can promote cGKI expression and to exclude nonspecific effects of p53DN or of gene silencing experiments, we transfected PC-12 cells with a p53 expression plasmid to overexpress $\mathrm{p} 53$ and monitored cGKI expression by both RT-PCR and quantitative RT-PCR as well as by immunoblotting. Results show that p53 significantly drives cGKI expression at both the mRNA and protein levels (Fig. $1 g-i$ ).

Together, these data show that $\mathrm{p} 53$ is critical for cGKI expression in PC-12 cells.

\section{p53 occupies specific responsive elements on cGKI and drives} its expression in primary neurons during maturation in vitro To investigate the p53-dependent cGKI transcriptional regulation in neurons and under conditions where physiological growth cone remodeling and neuronal maturation are required, further experiments were conducted in cultured primary neurons. By using a previously published algorithm (Hoh et al., 2002) (http://linkage.rockefeller.edu/p53), a set of putative p53 TFBS was identified on the CGKI gene on several intronic regions (Fig. 2a). Thus, we performed chromatin immunoprecipitation (ChIP) experiments in E18 cortical neurons at 3 DIV to examine whether p53 occupies these in silico predicted transcriptional binding sites on the cGKI gene. Results of ChIP followed by realtime PCR showed that endogenous p53 occupies several, but not all, in silico predicted binding sites on cGKI in a chromatin environment (Fig. 2b). Luciferase assays were also performed in PC-12 cells to investigate whether p53 would induce the expres- 

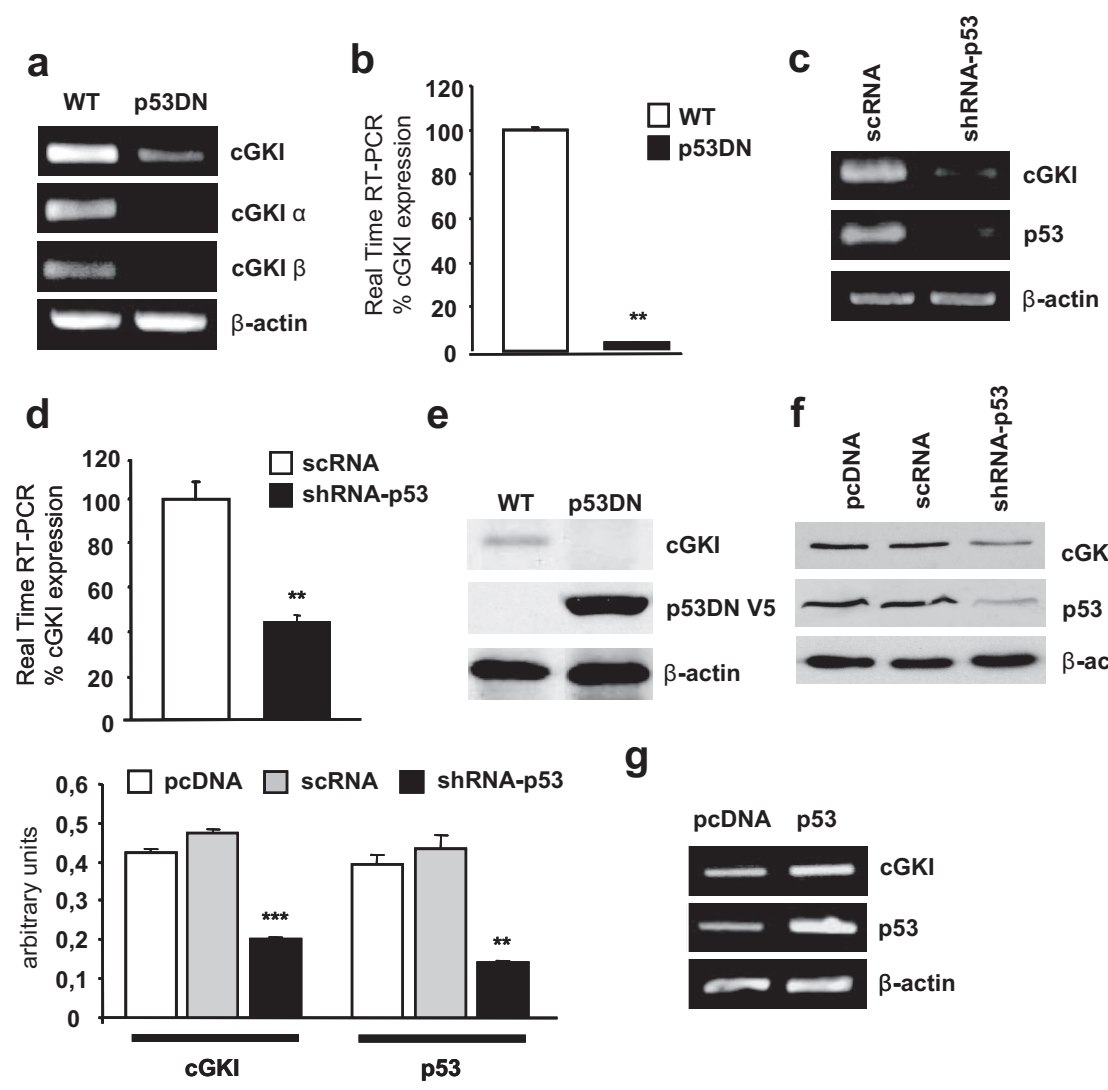

g
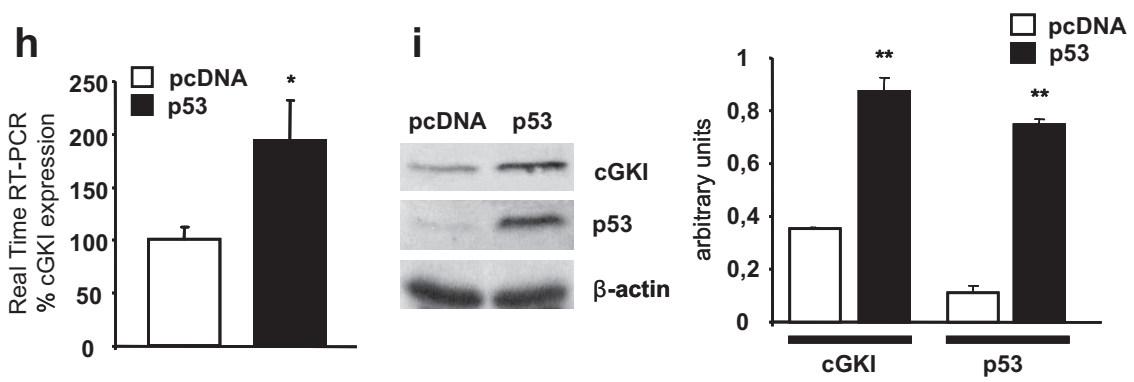

Figure 1. $\quad$ p53 regulates CGKI expression levels. $\boldsymbol{a}-\boldsymbol{f}, \mathrm{RT}-\mathrm{PCR}$ and real-time RT-PCR experiments show a significant decrease in mRNA expression for cGKI after both inhibition of p53 DNA binding $(\boldsymbol{a}, \boldsymbol{b})$ and p53 gene silencing $(\boldsymbol{c}, \boldsymbol{d})$ in p53DN stable and p53 shRNA transiently transfected, respectively, predifferentiated PC-12 cells. p53 scrambled shRNA (scRNA) was used as a control. Immunoblotting shows a marked suppression of CGKI expression in both p53DN stable $(\boldsymbol{e})$ and p53 shRNA transiently transfected (f) PC- 12 cells. Antibodies against V5 and $\mathrm{p} 53$ show expression levels of p53 DN $(\boldsymbol{e})$ and full-length $\mathrm{p} 53(\boldsymbol{f}, \boldsymbol{i})$, respectively. $\beta$-Actin was used as a loading control. Bar graph shows densitometric data analysis: intensity of representative bands for cGKI and p53 (f) was normalized to $\beta$-actin. $\boldsymbol{g}, \boldsymbol{h}, \mathrm{RT}$-PCR $(\boldsymbol{g})$ and real-time RT-PCR $(\boldsymbol{h})$ show increased cGKI expression levels in predifferentiated PC-12 cells transiently transfected with p53 WT. $i$, Immunoblotting reveals an induction of cGKI protein expression following p53 overexpression in predifferentiated PC-12 cells. $\beta$-Actin was used as a loading control. Bar graph shows densitometric data analysis: intensity of representative bands for $\mathrm{GKI}$ and $\mathrm{p} 53$ was normalized to $\beta$-actin. Experiments were performed in triplicate. Unpaired two-tailed $t$ test: ${ }^{*} p<0.05 ;{ }^{* *} p<0.01,{ }^{* * *} p<0.001$.

sion of a cGKI in silico predicted responsive element that showed occupancy by ChIP. Indeed, overexpression of p53 drove the luciferase signal of ChIP-positive sites (supplemental Fig. 1, available at www.jneurosci.org as supplemental material). These data support the positive transcriptional regulation of p53 upon specific consensus sequences on cGKI.

Then, we measured the expression profile of cGKI during maturation of embryonic (E18) cortical neurons in vitro. mRNA and protein expression profiles showed significant increase of cGKI levels between 3 and 14 DIV (Fig. $2 c, d$ ), a time when the neuronal network is well connected and neurons are mature, and when nuclear p53 is expressed, as previously observed (Di Giovanni et al., 2006).
Immunocytochemistry experiments revealed that cGKI is localized along processes and at the growth cone, likely to transduce signals in growing axons (Fig. $2 e, f)$. Then, we asked whether p53 would influence cGKI expression during neuronal maturation. By comparing E18 cortical neurons from p53-null with those from wild-type mice, indeed we found that absence of p53 impaired cGKI expression both at mRNA and protein level (Fig. $2 g-i$ ). To confirm these in vitro findings in vivo, immunoblotting was also performed in wild-type and p53-null mouse cortex at E18. Results show that cGKI expression is markedly reduced in p53-null cortex (Fig. 2j).

These results show that p53 occupies cGKI regulatory elements in primary neurons to drive its expression during neuronal maturation.

\section{p53 is required for cGMP signaling to counteract Sema3A-induced growth cone collapse in postnatal dorsal root ganglia}

To test whether p53 is indeed required for cGKI ability to counteract growth cone collapse, subsequent experiments were conducted using P7 DRG explants from wild-type and p53-null mice and Sema3A was used as a prototype growth cone collapse molecule.

First, we analyzed DRGs from p53-null versus wild-type mice. Morphological analysis showed that DRGs from p53-null mice develop shorter neurites compared with wild-type (Fig. $3 a, b$ ), while the size of the ganglia as well as the number and the size of individual cells did not differ from wild-type (data not shown). In addition, the outgrowth area was reduced in p53null DRGs $\left(969,27 \pm 294,07 \mathrm{~mm}^{2}\right.$ in-null vs $1647,34 \pm 282,15$ in WT) and growth cone analysis revealed significantly more collapsed growth cones in DRGs from p53-null versus wild-type mice $(27,27 \% \pm$ $0,89$ vs15,21 $\pm 2,98)$.

Then, we measured by quantitative RT-PCR as well as by immunoblotting the expression levels of cGKI in p53-null DRGs. We found that both the mRNA and protein expression of cGKI were significantly reduced compared with wild-type, demonstrating that $\mathrm{p} 53$ contributes to physiological expression of cGKI in DRG (Fig. $3 c, d$ ).

Next, the effects of Sema3A on growth cone collapse were tested in wild-type, p53-null and cGKI-null DRGs. Results show that Sema3A induces, as expected, growth cone collapse in p53null, cGKI-null and wild-type DRG explants (supplemental Fig. $2 a-c$, available at www.jneurosci.org as supplemental material). To test whether cGMP-cGKI signaling would prevent Sema3Ainduced growth cone collapse, we increased intracellular cGMP levels by delivering the membrane-permeable cGMP analog 8-Br-cGMP in combination with Sema3A. Importantly, we ob- 
served that 8-Br-cGMP protects from Sema3A-induced growth cone collapse only in wild-type, but not in p53-null and cGKI-null DRGs (supplemental Fig. 2b,c, available at www.jneurosci.org as supplemental material). These data suggest that p53-dependent cGKI expression is required for the ability of cGMP to prevent Sema3A-induced growth cone collapse.

Finally, we performed p53 rescue experiments in p53-null DRG explants to restore cGKI expression and verify whether this was sufficient to prevent growth cone collapse. p53-null DRG explants were infected with a bicistronic p53-GFP adenovirus, or with a control GFP adenovirus and treated with a combination of Sema3A, 8-Br-cGMP and the cGKI inhibitor KT 5823. In a parallel set of experiments, p53null DRG were infected with a cGKI adenovirus (cGKI $\alpha$ ) to verify whether cGKI overexpression would rescue growth cone collapse in p53-null neurons.

Indeed, p53 infection rescued cGKI expression (Fig. $4 a, b$ ), and when activated by 8 -Br-cGMP, restored cGKI prevented Sema3A-induced growth cone collapse (Fig. 4c). Furthermore, the administration of the cGKI inhibitor KT 5823 was able to block the protective effect of p53 reexpression on growth cone collapse (Fig. 4c), indicating that cGKI was responsible to counteract growth cone collapse. Finally, infection of p53-null DRGs with a cGKI adenovirus, which resulted in a strong increase in cGKI expression (Fig. $4 b$ ), was able to rescue Sema3A-induced growth cone collapse, while codelivery of KT 5823 blocked this effect (Fig. 4c).

Together, these data show that DRGs from p53-null mice are more susceptible to growth cone collapse than wild-type DRGs, and that p53 partially prevents growth cone collapse by driving the expression of cGKI.

\section{Discussion}

In neurons, cGMP-cGKI downstream signaling includes the phosphorylation of RhoA (Sawada et al., 2001), which inhibits RhoA activation protecting from growth cone collapse, and the phosphorylation of GSK3 $\beta$ that is essential for axonal branching in DRG neurons (Zhao et al., 2009). On the other hand, the transcriptional regulation of cGKI in neurons has remained largely elusive so far. In the present study we demonstrate that the tumor suppressor p53 transcriptionally regulates the expression level of cGKI in neuronal-like PC-12 cells and in primary neurons during neuronal maturation, and contributes to the inhibition of growth cone collapse elicited by Sema3A in DRG. SP-1 consensus sequences on the cGKI promoter region have been described (Sellak et al., 2002), but no transcription factor has been reported to regulate cGKI in a chromatin environment. Due to the multiple actions of cGKI in many cell types and tissues (Hofmann et al., 2006), it is p53 TFBS
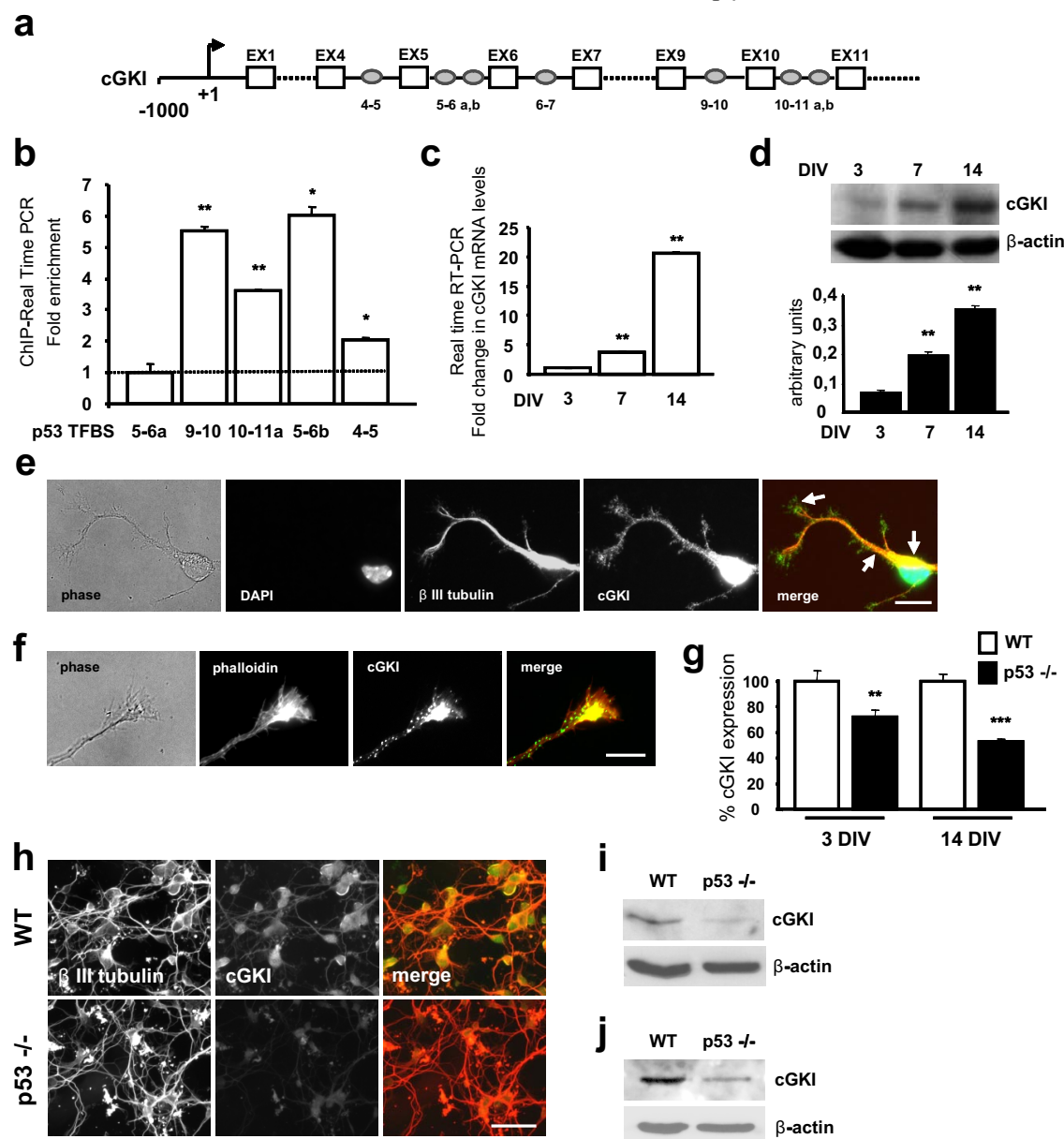

I WT p53

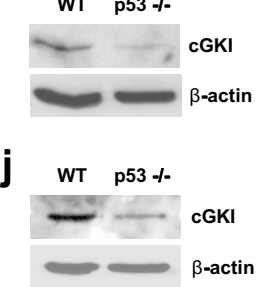

Figure 2. $\quad$ p53 occupies specific TFBS within the CGKI gene and regulates CGKI expression in primary neurons. $\boldsymbol{a}$, Schematic representation of putative $\mathrm{p} 53$ TFBS within the CGKI mouse gene. $\boldsymbol{b}$, A ChIP assay shows interaction in a chromatin environment of WT $p 53$ with some of the p53 TFBS derived from the cGKI gene. At 3 DIV, E18 cortical neurons were cross-linked with formaldehyde and immunoprecipitated with a polyclonal antibody recognizing full-length p53 (FL-393). The input samples were collected before c, Real-time RT-PCR experiments show the CGKI mRNA expression profile in E18 cortical neurons during maturation in vitro. Fold changes were normalized to 3 DIV. $\boldsymbol{d}$, Immunoblotting shows cGKI protein expression levels in E18 cortical neurons within 14 DIV. cytochemistry shows cGKI localization in the cell body, along processes and at the growth cone in an isolated single neuron $(\boldsymbol{e})$ and at a higher magnification at the growth cone of a single neuron $(\boldsymbol{f})$ (cultured E18 cortical neurons at 3 DIV). Scale bars: $\boldsymbol{e}, 20 \mu \mathrm{m}$ cortical neurons at 3 and 14DIV. $\boldsymbol{h}$, E18 mouse cortical neurons (3 DIV) from p53-null mice display diminished cGKI expression when 作 p53-null compared with WT (E18) cortical neurons at 3 DIV (i) as well as in E18 mouse cortex (j). Experiments were performed in triplicate. Unpaired two-tailed $t$ test: ${ }^{*} p<0.05$; $^{* *} p<0.01$; $^{* * *} p<0.001$.

likely that several transcription factors would contribute to regulate its expression.

Here, we show that p53 drives the expression of cGKI and occupies consensus sequences on several introns of the cGKI gene. This is rather typical of p53-dependent transcription, as p53 consensus binding sequences are often present on introns of target genes (Wang et al., 2001). This type of transcriptional regulation also supports data showing that $\mathrm{p} 53$ drives the expression of cGKI independently of the two isoforms, as these introns are common to both the $\alpha$ and $\beta$ isoform. p53 classically binds to specific DNA sequences to regulate transcription of target genes, which in turn triggers cell cycle arrest and DNA repair, promotes apoptosis, and influences differentiation (Xu, 2003; Harms et al., 2004; Riley et al., 2008). However, we have recently reported that 
a
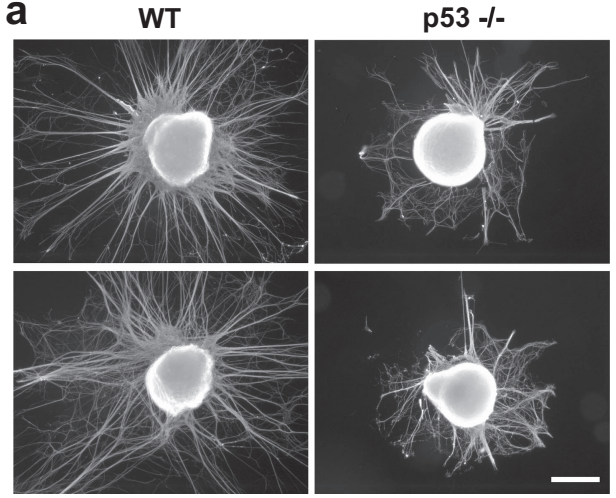

b

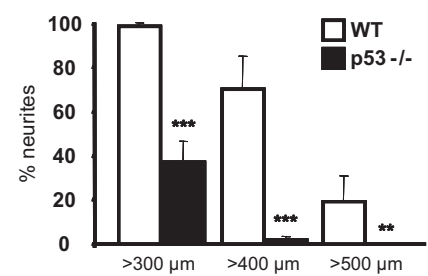

C

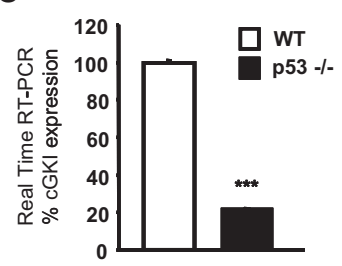

d

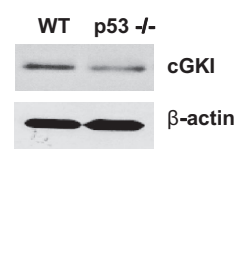

Figure 3. p53-null DRGs display outgrowth abnormalities and reduced cGKI expression levels. $\boldsymbol{a}, \beta$ III tubulin staining displays morphology of postnatal day 7 WT and p53-null DRG explants after $3 \mathrm{~d}$ in culture following NGF administration (50 $\mathrm{ng} / \mathrm{ml})$. For each genotype two representative examples are shown. Scale bar, $300 \mu \mathrm{m} . \boldsymbol{b}$, Bar graphs show neurite length of WT and p53-null DRG. c, Real-time RT-PCR experiments show a significant decrease in mRNA expression for cGKI in DRG explants of p53-null compared with WT mice. $\boldsymbol{d}$, Immunoblotting shows decreased levels of cGKI in DRG explants of p53-null compared with WT mice. $\beta$-Actin was used as a loading control. Experiments were performed in triplicate. Unpaired two-tailed $t$ test: ${ }^{* *} p<0.01 ;{ }^{* * *} p<0.001$.

$\mathbf{a}$
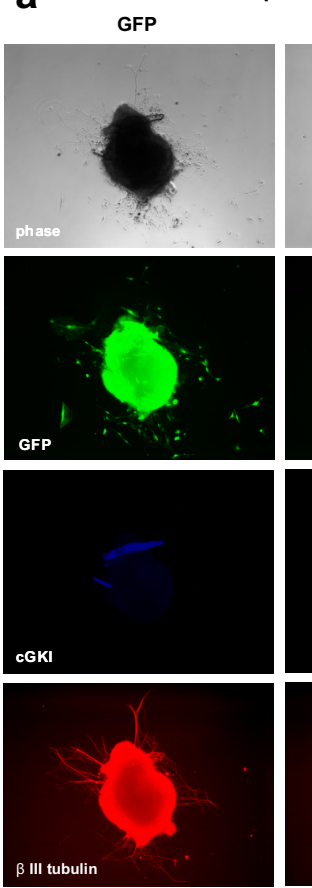

Figure 4. p53 restoration is sufficient to rescue cGKI expression and activity in p53-null DRG. $\boldsymbol{a}$, Immunocytochemistry shows restored cGKI expression levels in p53-infected p53-null DRG. Scale bar, $200 \mu \mathrm{m}$. $\boldsymbol{b}$, Immunoblotting shows restored CGKI levels in p53-null DRG infected with p53 adenovirus and overexpression of CGKI in DRG infected with cGKI adenovirus. c, Growth cone collapse assay in the presence of Sema3A alone, Sema3A/8-Br-cGMP, and Sema3A/8-Br-cGMP/KT 5823 using adenovirus-infected ( 553 and cGKI) P7 DRG explants from p53-null mice. Experiments were performed in triplicate (200-300 growth cones per group were counted). Unpaired two-tailed $t$ test: ${ }^{* *} p<0.01$; ${ }^{* * *} p<0.001$. p53 can affect the transcription of progrowth and cytoskeleton-associated proteins, which are required for neuronal outgrowth and peripheral nerve regeneration (Di Giovanni et al., 2006; Tedeschi et al., 2009). Nonetheless, during appropriate neuronal maturation and successful regeneration counteracting growth cone collapse triggered by repulsive cues is a major requirement. So far, there has been no evidence suggesting a role of p53mediated transcription in controlling the axonal growth cone response. Here we show that p53 is also able to drive the expression of cGKI (Figs. $1 g-i, 4 b$ ), which in turn is required for cGMP signaling to counteract growth cone collapse. Furthermore, by comparing wild-type and p53null cultured embryonic cortical neurons, we found that the absence of p53 impairs cGKI expression levels (Fig. $2 g-j$ ).

Importantly, our data also demonstrate that cGMP's ability to inhibit Sema3Ainduced growth cone collapse is p53dependent. DRGs from p53-null mice express lower cGKI levels compared with those from wild-type mice and elevation of intracellular cGMP levels is not sufficient, as in wild-type, to protect growth cones of p53-null DRGs from their collapse upon Sema3A administration (supplemental Fig. $2 a-c$, available at www. jneurosci.org as supplemental material). Interestingly, lower but not absent levels of cGKI correlate not with a reduction but with a lack of anti-collapsing effect of cGMP (supplemental Fig. $2 b$, available at www.jneurosci.org as supplemental material; Fig. 4c), suggesting that cGMP/ cGKI-mediated anti-collapsing effect is only observed above a certain threshold level of cGKI.

Moreover, the concept that p53 affects growth cone collapse through expression of cGKI is further supported by the finding that the cGKI inhibitor KT 5823 abolishes the p53-dependent anti-collapsing effect of cGMP (Fig. 4c). However, it is important to note that the efficiency and/or specificity of protein kinase inhibitors, including cGKI inhibitors, may be unpredictable and lower than expected in particular when administered to intact cells (Burkhardt et al., 2000; Bain et al., 2003, 2007; Valtcheva et al., 2009). Therefore, any conclusion drawn from the use of KT 5823 needs to be critically considered. However, adenoviral-mediated overexpression of cGKI in p53-null DRGs significantly rescues Sema3A-dependent growth cone collapse, suggesting that indeed cGKI is important for p53-dependent effects. 
In conclusion, our findings demonstrate a role for the tumor suppressor p53 in driving the expression of cGKI during neuronal maturation and in controlling cGMP-cGKI ability to counteract Sema3A-induced growth cone collapse. This study may provide novel molecular targets to promote neuronal outgrowth and foster target reinnervation in conditions where growth cone collapse is enhanced such as following CNS axonal injuries.

\section{References}

Bain J, McLauchlan H, Elliott M, Cohen P (2003) The specificities of protein kinase inhibitors: an update. Biochem J 371:199-204.

Bain J, Plater L, Elliott M, Shpiro N, Hastie CJ, McLauchlan H, Klevernic I, Arthur JS, Alessi DR, Cohen P (2007) The selectivity of protein kinase inhibitors: a further update. Biochem J 408:297-315.

Burkhardt M, Glazova M, Gambaryan S, Vollkommer T, Butt E, Bader B, Heermeier K, Lincoln TM, Walter U, Palmetshofer A (2000) KT5823 inhibits cGMP-dependent protein kinase activity in vitro but not in intact human platelets and rat mesangial cells. J Biol Chem 275:33536-33541.

Butt E, Geiger J, Jarchau T, Lohmann SM, Walter U (1993) The cGMPdependent protein kinase-gene, protein, and function. Neurochem Res 18:27-42.

Demyanenko GP, Halberstadt AI, Pryzwansky KB, Werner C, Hofmann F, Maness PF (2005) Abnormal neocortical development in mice lacking cGMP-dependent protein kinase I. Brain Res Dev Brain Res 160:1-8.

Di Giovanni S, Knights CD, Rao M, Yakovlev A, Beers J, Catania J, Avantaggiati ML, Faden AI (2006) The tumor suppressor protein p53 is required for neurite outgrowth and axon regeneration. EMBO J 25:4084-4096.

Feil R, Hartmann J, Luo C, Wolfsgruber W, Schilling K, Feil S, Barski JJ, Meyer M, Konnerth A, De Zeeuw CI, Hofmann F (2003) Impairment of LTD and cerebellar learning by Purkinje cell-specific ablation of cGMPdependent protein kinase I. J Cell Biol 163:295-302.

Feil S, Zimmermann P, Knorn A, Brummer S, Schlossmann J, Hofmann F, Feil R (2005) Distribution of cGMP-dependent protein kinase type I and its isoforms in the mouse brain and retina. Neuroscience 135:863-868.

Harms K, Nozell S, Chen X (2004) The common and distinct target genes of the p53 family transcription factors. Cell Mol Life Sci 61:822-842.

Hofmann F, Feil R, Kleppisch T, Schlossmann J (2006) Function of cGMPdependent protein kinases as revealed by gene deletion. Physiol Rev 86:1-23.

Hoh J, Jin S, Parrado T, Edington J, Levine AJ, Ott J (2002) The p53MH algorithm and its application in detecting p53-responsive genes. Proc Natl Acad Sci U S A 99:8467-8472.

Hughes AL, Gollapudi L, Sladek TL, Neet KE (2000) Mediation of nerve growth factor-driven cell cycle arrest in PC12 cells by p53. Simultaneous differentiation and proliferation subsequent to $\mathrm{p} 53$ functional inactivation. J Biol Chem 275:37829-37837.

Luo Y, Raible D, Raper JA (1993) Collapsin: a protein in brain that induces the collapse and paralysis of neuronal growth cones. Cell 75:217-227.
Paul C, Schöberl F, Weinmeister P, Micale V, Wotjak CT, Hofmann F, Kleppisch T (2008) Signaling through cGMP-dependent protein kinase I in the amygdala is critical for auditory-cued fear memory and long-term potentiation. J Neurosci 28:14202-14212.

Riley T, Sontag E, Chen P, Levine A (2008) Transcriptional control of human p53-regulated genes. Nat Rev Mol Cell Biol 9:402-412.

Sawada N, Itoh H, Yamashita J, Doi K, Inoue M, Masatsugu K, Fukunaga Y, Sakaguchi S, Sone M, Yamahara K, Yurugi T, Nakao K (2001) cGMPdependent protein kinase phosphorylates and inactivates RhoA. Biochem Biophys Res Commun 280:798-805.

Schmidt H, Werner M, Heppenstall PA, Henning M, Moré MI, Kühbandner S, Lewin GR, Hofmann F, Feil R, Rathjen FG (2002) cGMP-mediated signaling via cGKIalpha is required for the guidance and connectivity of sensory axons. J Cell Biol 159:489-498.

Schmidt H, Stonkute A, Jüttner R, Schäffer S, Buttgereit J, Feil R, Hofmann F, Rathjen FG (2007) The receptor guanylyl cyclase Npr2 is essential for sensory axon bifurcation within the spinal cord. J Cell Biol 179:331-340.

Sellak H, Yang X, Cao X, Cornwell T, Soff GA, Lincoln T (2002) Sp1 transcription factor as a molecular target for nitric oxide- and cyclic nucleotide-mediated suppression of cGMP-dependent protein kinase-Ialpha expression in vascular smooth muscle cells. Circ Res 90:405-412.

Song H, Ming G, He Z, Lehmann M, McKerracher L, Tessier-Lavigne M, Poo M (1998) Conversion of neuronal growth cone responses from repulsion to attraction by cyclic nucleotides. Science 281:1515-1518.

Tedeschi A, Nguyen T, Puttagunta R, Gaub P, Di Giovanni S (2009) A p53$\mathrm{CBP} / \mathrm{p} 300$ transcription module is required for GAP-43 expression, axon outgrowth, and regeneration. Cell Death Differ 26:543-554.

Valtcheva N, Nestorov P, Beck A, Russwurm M, Hillenbrand M, Weinmeister P, Feil R (2009) The commonly used cGMP-dependent protein kinase type I (cGKI) inhibitor Rp-8-Br-PET-cGMPS can activate cGKI in vitro and in intact cells. J Biol Chem 284:556-562.

Wang L, Wu Q, Qiu P, Mirza A, McGuirk M, Kirschmeier P, Greene JR, Wang Y, Pickett CB, Liu S (2001) Analyses of p53 target genes in the human genome by bioinformatic and microarray approaches. J Biol Chem 276:43604-43610.

Wegener JW, Nawrath H, Wolfsgruber W, Kühbandner S, Werner C, Hofmann F, Feil R (2002) cGMP-dependent protein kinase I mediates the negative inotropic effect of cGMP in the murine myocardium. Circ Res 90:18-20.

Xu Y (2003) Regulation of p53 responses by post-translational modifications. Cell Death Differ 10:400-403.

Yamazaki M, Chiba K, Mohri T, Hatanaka H (2004) Cyclic GMPdependent neurite outgrowth by genipin and nerve growth factor in PC12h cells. Eur J Pharmacol 488:35-43.

Zhao Z, Wang Z, Gu Y, Feil R, Hofmann F, Ma L (2009) Regulate axon branching by the cyclic GMP pathway via inhibition of glycogen synthase kinase 3 in dorsal root ganglion sensory neurons. J Neurosci 29:13501360. 